\title{
PROJETO ALFADOWN: UMA REFERÊNCIA EM INCLUSÃO SOCIAL
}

\author{
Juliana de Souza Santos Hannum ${ }^{1}$ \\ ORCID: 0000-0002-4704-6044 \\ Luciana Novais de Oliveira Brito ${ }^{2}$ \\ ORCID: 0000-0003-3176-8189 \\ Renata Cardoso Barreto 3 \\ ORCID: 0000-0003-1559-0552
}

Resumo: Este relato O projeto "A informática como Processo Facilitador da Alfabetização de Pessoas com Síndrome de Down - ALFADOWN" compõe a extensão universitária como parte integrante do Programa de Referência em Inclusão Social (PRIS/CDEX/PROEX) da PUC Goiás. Este projeto propõe integrar a comunidade acadêmica e a comunidade em geral, com foco no apoio à aquisição da linguagem escrita das pessoas com Síndrome de Down (SD) e no desenvolvimento de habilidades sociais a fim de favorecer a participação social desses sujeitos a partir do letramento digital. O Alfadown tem como eixo condutor seu trabalho educativo que articula o ensino, a pesquisa e a extensão da PUC-Go. Nesse contexto, o foco do trabalho é ampliar as aprendizagens e a participação dos atores sociais que compõem o projeto Alfadown, seja os educandos na aquisição da linguagem escrita a partir do letramento digital e no desenvolvimento de habilidades sociais; seja os acadêmicos na mediação e na aproximação de sua formação profissional; seja as famílias no alargamento de seu repertório de incentivo ao desenvolvimento de seus filhos com Síndrome de Down. O intuito do Alfadown é contribuir no livre trânsito das pessoas com Síndrome de Down na cultura escrita e, consequentemente, na sociedade como um todo. Essa imersão na cultura escrita passa necessariamente pela

1 Juliana Santos de S. Hannum, Psicóloga, Doutora em Psicologia, Coordenadora do Programa de Referência em Inclusão Social, Pontifícia Universidade Católica de Goiás, Goiânia, Goiás, Brasil e-mail: dra.julianahannum@yahoo.com.br

2 Luciana Novais de O. Brito, Psicóloga, Doutoranda em Psicologia, Coordenadora do Projeto Alfadown, Pontifícia Universidade Católica de Goiás, Goiânia, Goiás, Brasil

3 Renata Cardoso Barreto, Pedagoga, Especialista em Psicopedagogia, Professora do Projeto Alfadown, Pontifícia Universidade Católica de Goiás, Goiânia, Goiás, Brasil 
compreensão no ato da leitura, pela expressão textual e pela consideração da alfabetização na perspectiva do letramento escrito e digital.

Palavras-chave: Síndrome de Down. Inclusão Digital. Letramento.

\title{
ALFADOWN PROJECT: A REFERENCE FOR SOCIAL INCLUSION
}

\begin{abstract}
The project "Information technology as a faciliatory process of literacy acquisition for people with Down Syndrome - ALFADOWN" comprises the university extension as an integral part of the Social Inclusion Program (PRIS/CDEX/PROEX) of the Pontifical Catholic University of Goiás-PUC-GO. This project proposes to integrate the academic community and community at large, with a focus on supporting the acquisition of written language for people with Down syndrome (DS), as well as the development of social skills in order to promote their social participation through digital literacy. The driving force of Alfadown is the educational work that articulates the teaching, research and the extension program of PUCGO. In this context, the focus of the work is to increase the learning and the participation of the social elements that make up the project Alfadown, be they the students in the process of written language acquisition through digital literacy and social skills development; be they the academics in the process of their professional training; or be they the families in the process of increasing their repertoires to encourage the development of their children with Down Syndrome. The purpose of Alfadown is to contribute to the mobility of people with Down Syndrome in the written culture and, consequently, in society as a whole. This immersion in the written culture necessarily involves comprehension in the act of reading, writing, and in the consideration of literacy from the perspective of the written literacy and digital literacy.
\end{abstract}

Keywords: Down Syndrome. Digital inclusion. literacy.

\section{PROYECTO ALFADOWN: UNA REFERENCIA EN INCLUSIÓN SOCIAL}

Resumen: El proyecto "La informática como Proceso Facilitador de la Alfabetización de Personas con Síndrome de Down - ALFADOWN" compone la extensión universitaria como parte integrante del Programa de Referencia en Inclusión Social (PRIS / CDEX / PROEX) de la PUC Goiás. Este proyecto propone integrar la comunidad académica y la comunidad en general, con foco en el apoyo a la adquisición del lenguaje escrito de las personas con Síndrome de Down (SD) y en el desarrollo de habilidades sociales a favor de favorecer la participación social de esos sujetos a partir del letramento digital. El Alfadown tiene como eje conductor su trabajo educativo que articula la enseñanza, la investigación y la extensión de la PUC-Go. En este contexto, el foco del trabajo es ampliar los aprendizajes y la participación de los actores sociales que componen el proyecto Alfadown, sea los educandos en la adquisición del lenguaje escrito a partir del letramento digital y en el desarrollo de habilidades sociales; sea los académicos en la mediación y en la aproximación de su formación profesional; es decir, las familias en la ampliación de su repertorio de incentivo al desarrollo de sus hijos con Síndrome de Down. La intención de Alfadown es contribuir en el libre tránsito de las personas con Síndrome de Down en la cultura escrita y, consecuentemente, en la sociedad como un todo. Esta inmersión en la cultura 
escrita pasa necesariamente por la comprensión en el acto de la lectura, por la expresión textual y por la consideración de la alfabetización en la perspectiva del texto escrito y digital.

Palabras clave: Síndrome de Down. Inclusión Digital. Letramento.

Submetido em: 16/12/2018

Aceito em: 21/12/2018.

\section{INTRODUÇÃO}

Atualmente, vive-se a era da informação, ou conforme Castells (2003, p.235) da sociedade informacional, na qual "a apropriação e inclusão/exclusão de oportunidades e vantagens, as chances de cada pessoa na sociedade são amplamente influenciadas pelo acesso tecnológico, em especial, ao mundo digital". Nesse contexto, a inclusão digital, também pode ser denominada de letramento digital, tendo efeito semelhante à alfabetização escolar no processo de inclusão social, isso porque a inclusão digital está relacionada à questão da cidadania, do direito à informação e de acesso à Instituição Universitária. Para as pessoas com necessidades educacionais especiais (NEEs), as dificuldades no uso de computadores vão para além do acesso às máquinas e à rede, pois elas apresentam diferentes tipos de deficiências para as quais os softwares e hardwares, de forma geral, não estão preparados. O desafio passa então ao desenvolvimento de novas ferramentas que permitam a apropriação dos conceitos e habilidades inerentes à informática para NEEs.

Segundo estudos na área de educação especial, o desenvolvimento cognitivo das pessoas com Síndrome de Down apresenta um transcurso mais lento. No entanto, embora a Síndrome de Down seja uma consequência genética, a literatura ressalta que o ambiente sociocultural favorece e influencia o desenvolvimento de habilidades e capacidades do indivíduo. Diante dessa perspectiva, pode-se considerar que a riqueza do meio sociocultural vivenciado por esses indivíduos contribui para promover e ampliar o desenvolvimento cognitivo. Nesse sentido, o projeto Alfadown é percebido como inovador, pois, tem como público alvo as pessoas com Síndrome de Down, isso quer dizer que todos os esforços são centrados para a contribuição da formação desses educandos, tendo como viés de trabalho a oferta de um suporte no processo de alfabetização na perspectiva do letramento e da inclusão digital. Embora as pessoas com síndrome de Down tenham algumas características físicas semelhantes e níveis variados de 
comprometimento intelectual, todas podem aprender. Sendo assim, nosso pressuposto é de que cada sujeito é único, portanto, seus processos de aprendizagem são marcados pelas suas singularidades individuais e contextuais. Como qualquer outro educando, quanto maior a relação de proximidade e de interação, maior a possibilidade de internalização do conhecimento e de aprendizagem.

Um intuito fundamental e de inovação do trabalho do Alfadown é oferecer um ambiente de convivência e de interação entre os educandos com Síndrome de Down e os acadêmicos da PUC Goiás, para que eles possam desenvolver suas habilidades sociais a partir de trocas interpessoais em um grupo social amplo e diversificado e além de se estimular o uso e a reflexão sobre a leitura e a escrita, tendo o computador como uma ferramenta educacional importante, estrategicamente pensado para permitir um maior engajamento dos educandos no trabalho com a cultura escrita.

\section{PROJETO ALFADOWN: UMA REFERÊNCIA EM INCLUSÃO SOCIAL}

A Pró-reitoria de Extensão e Apoio Estudantil, reconhecendo a importância de articular ações que possibilitam a inclusão social, nesse sentido, 22 de março de 2014 cria o Programa de Referência a Inclusão Social (PRIS) como um Programa Permanente de Extensão. Conforme a Política de Extensão da Pontifícia Universidade Católica de Goiás (PUC Goiás), a extensão "compreende dois aspectos fundamentais do projeto pedagógico da Universidade: qualidade acadêmico-científica e compromisso social, relacionando os grandes temas sociopolíticos e culturais com os processos educativos" (UCG, 2006). Em relação ao primeiro aspecto, "a Extensão, metodologicamente, desenvolve-se, inscrita nos processos educativos e formativos, nos cursos e áreas de conhecimento, envolvendo professores, alunos, funcionários e sociedade".

No contexto acima mencionado, o PRIS apresenta-se representativo do compromisso socioeducacional da PUC Goiás com a sociedade da qual essa Universidade é parte, em específico com uma parcela populacional historicamente marginalizada e com poucas opções de acesso a recursos que contribuam para o atendimento a necessidades específicas, tais como as relacionadas à saúde, educação, esporte, acesso cultural, lazer e acessibilidade (transporte, mobilidade física). Ao mesmo tempo, o Programa tem por um de seus objetivos fortalecer o 
vínculo com a formação acadêmica no campo do ensino e da pesquisa à medida que abre campos de estágio que possibilitam diferenciais de excelência na capacitação profissional, formação humana e exercício da cidadania.

Sob este prisma, os trabalhos do PRIS buscam contribuir com duas vertentes importantes na inclusão em relação aos atendidos: primeiramente, garantindo a possibilidade de desenvolvimento dos potenciais dos participantes - por exemplo: linguístico, físico, cognitivo, artístico, de interação, bem-estar. Segundo, porque em consequência deste desenvolvimento essas pessoas estarão mais preparadas e seguras para desempenhar papeis sociais, gerenciar suas vidas e garantir seus direitos. Nesse ciclo, quanto mais precoce e intensamente as pessoas assumirem o protagonismo de suas histórias, maiores as suas chances de conquista de respeito e participação social.

Cabe ressaltar ainda uma terceira vertente, relacionada à formação dos prestadores do atendimento (acadêmicos, voluntários e profissionais), as ações do PRIS objetivam favorecer o desenvolvimento de um olhar solidário, com alicerce na alteridade - a noção de que as diferenças do outro são constitutivas da sua humanidade, e vice-versa. Afinal, como afirma Meneguetti (2004, p. 98): "A diferença é a absoluta comprovação da realidade. A grande tese, portanto, é a necessidade da inclusão da diferença como uma maneira de interpretar os significados da vida, a fim de que seja possível olhar o real em sua integralidade". Nesse reconhecimento, o compromisso formador deste Programa de Extensão não se restringe a uma capacitação para o mundo do trabalho, mas amplia-se na dimensão atitudinal humanitária, de favorecer ações e atitudes cúmplices - na vida pessoal, profissional e social - para com os direitos, qualidade de vida e fortalecimento de potenciais de pessoas e grupos em situação de exclusão. Abre-se também à possibilidade de contribuir na formação continuada de profissionais da educação e de outras áreas que atuem com público similar aos atendidos pelo Programa, inclusive por meio de assessoria.

Pelo compromisso social que marca o agir extensionista da PUC Goiás, objetiva-se, ainda, que o trabalho e reflexões produzidas pelo PRIS possam contribuir para o fortalecimento do debate local, regional e nacional acerca dos diversos e controversos aspectos que envolvem a Inclusão.

Sob esta perspectiva, o PRIS reconhece que a defesa de princípios constitucionais garante aos seus participantes - público atendido e prestadores do atendimento - oportunidades que contribuem com a formação de novos cidadãos que mutuamente se educam sob outros olhares, paradigmas e ideais em prol da 
cidadania exercida na diversidade. Como salienta Boff (2004, p. 8), "Em todos os âmbitos da vida precisamos de pessoas críticas, criativas e cuidantes. É condição para a cidadania plena e para a sociedade que sempre se renova”.

Tal concepção estabelece a garantia de direitos e contribui com o protagonismo, aspecto fundamental que auxilia a formação sujeitos de direito e dignidade, independente das diferenças. Avançar nesta direção significa incluir e inaugura a possibilidade de todos se pronunciarem com mais autonomia na sociedade e na própria vida.

O PRIS atua, por meio de suas diversas ações e projetos, como o caso do Projeto Alfadown, na perspectiva de impulsionar a participação social dos educandos, entendendo essa participação social como a possibilidade de cidadania e inserção nas práticas sociais que visam à transformação da própria sociedade e dos sujeitos.

Nesse sentido, o Programa considera pertinente o reconhecimento dos aspectos históricos, sociais, culturais e econômicos no engendramento dos mecanismos de inclusão/exclusão, que devem ser analisados e compreendidos em suas múltiplas determinações, o que confere um caráter interdisciplinar ao PRIS.

Ao considerar essas múltiplas determinações entendemos que a inclusão social é um campo de muitos embates e de disputa de diferentes atores sociais que buscam o reconhecimento de sua alteridade e de seus direitos de cidadania, num contexto histórico onde a exclusão, que é própria do sistema econômico, precisa reproduzir-se para manter-se:

A naturalização do fenômeno da exclusão e o papel do estigma servem para explicitar, especificamente no caso da sociedade brasileira, a natureza da incidência dos mecanismos que promovem o ciclo de reprodução da exclusão, representado pela aceitação tanto ao nível social, como do próprio excluído, expressa em afirmações como isso é assim e não há nada para fazer (WANDERLEY, 2001, p. 17-27).

Diante disso, compreendemos que historicamente as pessoas com necessidades educacionais específicas foram sendo estigmatizadas e excluídas de nossos mercados materiais e simbólicos e entendidas como problema social e do campo apenas da assistência.

O Programa de Referência em Inclusão Social quer, por meio de seus Projetos, reafirmar a alteridade/identidade dos sujeitos aqui atendidos, estabelecendo o compromisso com a mobilização social e com a transformação histórica, 
propiciando aos educandos atendidos por nós novas possibilidades de participação social na luta contra a garantia dos direitos e pela cidadania plena.

Ao dominar os artefatos simbólicos produzidos pela humanidade os sujeitos com necessidades específicas se tornam sujeitos de um tempo e porta-vozes de seus anseios e possibilidades, adentrando o universo do conhecimento, da cultura, da informação e do mundo do trabalho.

O Alfadown, na condução do trabalho em apoio à alfabetização, está propiciando aos educandos que se tornem partícipes de seu tempo e sujeitos de sua história, uma vez que passam a dominar os códigos linguísticos e, portanto, se inserem nas práticas sociais com condições de interagir, dialogar e intervir, o que movimenta a história e impacta no avanço para uma sociedade cada vez mais inclusiva.

\section{PROJETO ALFADOWN}

O projeto "A informática como Processo Facilitador da Alfabetização de Pessoas com Síndrome de Down - ALFADOWN” compõe a extensão universitária como parte integrante do Programa de Referência em Inclusão Social (PRIS/CDEX/PROEX) da PUC Goiás. Este projeto propõe integrar a comunidade acadêmica e a comunidade em geral, com foco no apoio à aquisição da linguagem escrita das pessoas com Síndrome de Down (SD) e no desenvolvimento de habilidades sociais a fim de favorecer a participação social desses sujeitos a partir do letramento digital.

O Alfadown foi instituído em 2003 e nasceu de uma parceria com a Associação Down de Goiás (ASDOWN). O Alfadown tem uma trajetória histórica com mais de uma década de existência e que trouxe inovação não só à Pontifícia Universidade Católica de Goiás, mas especialmente à comunidade goianiense.

O Alfadown é um projeto inovador por sua natureza interdisciplinar e ao se tornar ponto de intersecção entre a extensão, o ensino e a pesquisa com a articulação de diversos cursos e escolas da PUC GO. Nesse contexto, articulam-se e apoiam o Alfadown, em especial, as Escolas de Ciências Sociais e da Saúde, de Formação de Professores e Humanidades, de Ciências Agrárias e Biológicas e de Ciências Exatas e da Computação, na oferta de um trabalho que só não bebe nas fontes mais atualizadas no campo pedagógico, como também promove pesquisas que geram resultados que impactam diretamente na melhoria da qualidade de vida dos educandos com SD e das famílias atendidas. 
Os sujeitos atendidos no Alfadown encontram serviços educacionais gratuitos de suporte ao processo de alfabetização com o uso de aplicativos desenvolvidos especificamente para o Alfadown, bem como encaminhamento para outras ações que a PUC Goiás oferece nas áreas de fonoaudiologia, psicologia e exames clínicos e laboratoriais na área da genética. A extensão universitária é uma grande parceira que repercute sócio e economicamente na vida das famílias, que muitas vezes não possuem condições socioeconômicas adequadas para adquirir esses serviços na rede privada ou se deparam com restrições qualitativas e quantitativas de oferta na rede pública. Por meio do Alfadown, pessoas NEEs vivenciam a inclusão e intensificação da participação social.

A gama de trabalhos e atividades do Alfadown mobilizam a vida acadêmica que demanda dos estudantes, professores e pesquisadores a aplicação prática dos seus conhecimentos decorrente de seus estudos e pesquisas. Adicionalmente, o projeto Alfadown também proporciona um campo de pesquisa, que já inclui fomentos da FAPEG (Fundação de Amparo à Pesquisa do Estado de Goiás). Um importante projeto de estudo em andamento no Alfadown tem como foco principal contribuir para uma melhor compreensão da Educação Digital Inclusiva na Síndrome de Down, possibilitando a capacitação de profissionais envolvidos com a formação continuada de professores, assim como estudantes de graduação e pós-graduação da região Centro-Oeste, em especial, do Estado de Goiás.

Em parceria com docentes e discentes dos cursos de Ciência e Engenharia da Computação (PUC Goiás), estão sendo desenvolvidos modelos computacionais, software e dispositivos (hardware) que possibilitam investigar, quantificar e analisar o comportamento e as emoções de pessoas com SD, quando submetidas às atividades por intermédio do computador. No futuro, esta tecnologia de biofeedback poderá ser utilizada no monitoramento à distância e na customização automática das atividades desenvolvidas em sistemas computacionais, como, por exemplo, em videogames, em tablets e em outros computadores pessoais. Concomitantemente, estão sendo desenvolvidos aplicativos customizados para os requisitos do projeto Alfadown, com suporte ao biofeedback.

Os aplicativos (software) têm como objetivo aumentar a atenção, a prontidão e o engajamento dos alunos, por meio de novas interfaces e tecnologias que amplificam o estímulo multimídia durante a execução de tarefas no computador. Além disso, o desenvolvimento desses aplicativos considera a possibilidade de incorporação das metodologias atuais e de novas metodologias, utilizadas no ensino-aprendizagem, na avaliação clínica e na prática terapêutica. Por outro 
lado, o envolvimento de discentes e docentes da Computação agrega formação ética, comprometimento social e interesse político a estes profissionais. Portanto, cumpre ressaltar que o projeto Alfadown propõe e utiliza uma visão inovadora acerca da Inclusão Digital, por meio de uma "via de mão dupla”. Para ter completude e perenidade, a Inclusão Digital deve criar e/ou adaptar as novas tecnologias às pessoas e não apenas adaptar as pessoas às novas tecnologias.

Dessa forma, o projeto Alfadown tornou-se um espaço de convívio, de integração, de reflexão, de estudos e pesquisas sobre o processo de aprendizado das pessoas com Síndrome de Down. Trata-se de um projeto que apresenta inovação em suas metodologias, possibilita a prática de seus alunos da graduação no contexto educativo e promove a qualidade de vida para seus educandos e familiares participantes do projeto.

O Alfadown tem como eixo condutor seu trabalho educativo que articula o ensino, a pesquisa e a extensão da PUC. Nesse contexto, o objetivo do trabalho é oferecer um apoio ao processo de aquisição da linguagem escrita pelos educandos Down tendo como recursos privilegiados as tecnologias digitais, em especial a ferramenta computacional.

O nosso objetivo é ampliar as aprendizagens e a participação dos atores sociais que compõem o projeto Alfadown, seja os educandos na aquisição da linguagem escrita a partir do letramento digital e no desenvolvimento de habilidades sociais; seja os acadêmicos na mediação e na aproximação de sua formação profissional; seja as famílias no alargamento de seu repertório de incentivo ao desenvolvimento de seus filhos com Síndrome de Down.

Oferecer um suporte para o processo de alfabetização dos educandos com Síndrome de Down ampliando as relações dos mesmos com a linguagem escrita proporcionadas em outros espaços sociais a partir (tem continuação?)

Desenvolver atividades pedagógicas coletivas de trocas sociais, de intercâmbio cultural e de incentivo à leitura e à escrita entre os educandos e acadêmicos.

Utilizar o computador como uma ferramenta educacional para favorecer o processo ensino-aprendizagem e a intervenção pedagógica no campo da alfabetização.

Oferecer um grupo psicoeducativo que trabalha com o acolhimento e a mediação aos pais e cuidadores dos educandos com Síndrome de Down para promover a conscientização sobre o papel da família no processo de desenvolvimento do educando e as possibilidades de maior atuação social. 
Consolidar o grupo de estudo sobre o processo de ensino-aprendizagem de pessoas com Síndrome de Down, proporcionando um embasamento teórico-prático sobre questões relativas à Inclusão.

Utilizar softwares educacionais e atividades singulares a cada educando que são elaboradas pelos acadêmicos supervisionados pelos professores e pesquisadores da PUC GO.

\section{MÉTODO}

\section{Participantes}

Participam deste projeto educandos com Síndrome de Down, acadêmicos dos diversos cursos de graduação e pós-graduação da Pontifícia Universidade Católica de Goiás, as famílias dos educandos e pesquisadores de diferentes cursos.

\section{Procedimentos Metodológicos}

A cada início de semestre, os acadêmicos selecionados vivenciam uma formação para o trabalho voltado para a aquisição da linguagem escrita dos educandos com SD. Nessa formação é abordada a alfabetização na perspectiva do letramento, como trabalhar com a ferramenta computacional e os diversos recursos que a mesma oferece para o letramento digital. Com esse subsídio, o atendimento é realizado por meio de atividades desenvolvidas pelos acadêmicos/voluntários do projeto Alfadown.

Os encontros entre os educandos e os acadêmicos são de 1 h30 e ocorrem duas vezes por semana na Área II da PUC Goiás, onde são desenvolvidas atividades coletivas integradoras e atendimento individualizado de suporte ao processo de alfabetização com os acadêmicos a partir do uso de ferramentas educacionais, em especial, o computador.

Atualmente, o Alfadown conta com quatro turmas, duas no turno matuti-

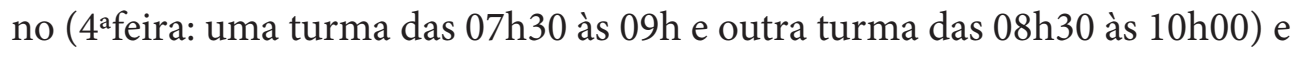
duas no turno vespertino ( $3^{\text {a }}$ feira: uma turma das $13 \mathrm{~h} 30$ às $15 \mathrm{~h}$ e outra turma das 14:30 às 16h00). O primeiro momento do atendimento é realizado de forma coletiva em que os educandos vivenciam atividades integradoras em que a prioridade é a ampliação da sociabilidade, a troca interpessoal, alargamento do leque de interação e desenvolvimento de habilidades sociais. 
Na sequência, inicia-se um trabalho pedagógico individual utilizando os recursos computacionais que visam o desenvolvimento da expressão oral, escrita e do trânsito no universo digital, o qual ocorre a partir da navegação na internet, recorrendo especialmente às ferramentas de busca e intercâmbio entre os educandos com o uso das redes sociais, visitas a sites e jogos educativos; programas diversos do Microsoft Office como Word, Power Point, One Note, o programa do Microsoft Paint, Paint Brush, dentre outros.

Além dessas ferramentas, também são utilizados aplicativos desenvolvidos para tarefas específicas, com suporte na plataforma Android/RemixOS. Estes atendem a requisitos específicos dos educandos e dos tutores envolvidos no projeto Alfadown, ofertando funcionalidades peculiares, como, o pareamento de vogais e a identificação e a compreensão do contexto. Além dessas, outras funcionalidades que possibilitam a verificação de variáveis de controle concomitantemente com a execução das tarefas no computador. Por exemplo, o registro de vídeo e voz, a frequência cardíaca, a identificação automática de expressões faciais, entre outros. Isto é chamado de retorno dos marcadores de comportamento e emoções, com base em parâmetros fisiológicos. Em inglês, biofeedback.

Nota-se que a aquisição da linguagem escrita a partir das ferramentas computacionais ultrapassam as conquistas no campo motor, ela favorece o desenvolvimento cognitivo, emocional e social a medida que a aquisição da escrita - que é um bem cultural constituído com um sistema simbólico de signos compartilhado por uma comunidade - torna-se uma das condições que permite o sujeito acessar, produzir e difundir as informações e os conhecimentos, consequentemente, a atuação social é mais efetiva ampliando a qualidade de vida de quem a domina. Portanto, o aprendizado desse bem cultural é complexo e fruto da constante interação com sistema, o qual tem funções comunicativas, expressivas, de constituições psíquicas e organizacionais que a todo tempo são demandadas no contexto da sociedade urbana. Inseridos no projeto Alfadown, os acadêmicos vivenciam os fundamentos didáticos de planejamento, mediação e avaliação do trabalho.

A metodologia empregada se dá a partir da perspectiva do letramento no campo da alfabetização que indica o rompimento das práticas educativas tradicionais repetitivas focadas apenas na mecânica da linguagem escrita, que foca nos usos sociais em que a escrita é demandada e nos interesses dos educandos. A escrita comparece na utilização da ferramenta computacional a partir de práticas sociais de interação, como por exemplo, na escrita do nome próprio, 
de mensagens para os colegas, de produção de relatos etc, complementando a aprendizagem escolar. Nesse sentido, os educandos com SD encontraram uma alternativa a mais para estarem em condições de fazer parte de uma sociedade informatizada, e assim ser possível a inclusão através dos recursos que a tecnologia nos oferece.

Para os acadêmicos oportuniza-se contato com a rede inclusiva mediante a alfabetização pela rede digital, contribuindo para a sua formação profissional com a diversidade. A participação dos estudantes dos diversos cursos no projeto Alfadown como voluntários enriquece o repertório de atuação profissional, com efeitos positivos no campo pessoal, acadêmico e profissional.

Para os familiares dos educandos, o projeto Alfadown é um lócus de trocas de experiências e de conhecimentos, já que os mediadores desse grupo são acadêmicos do curso de Psicologia sob supervisão dos professores da PUC GO. Assim, enquanto o atendimento aos educandos ocorre na sala de desenvolvimento de habilidades sociais e nos laboratórios de informática, os familiares responsáveis pelos mesmos também estão atuando no grupo psicoeducativo para discussões de temas importantes sobre a maior inserção social do sujeito com síndrome de Down.

\section{RESULTADOS E DISCUSSÕES}

O presente projeto visou fortalecimento de grupos de pesquisa e extensão da PUC Goiás. Assim, como a oferta de serviços e o preparo de recursos humanos especializados voltados para a Educação Digital Inclusiva.

O foco inovador deste projeto tem sido contribuir para uma melhor compreensão da Educação Digital Inclusiva na Síndrome de Down, possibilitando a capacitação de profissionais envolvidos com a formação continuada de professores, assim como estudantes de graduação e pós-graduação da região Centro-Oeste, em especial, do Estado de Goiás. Adicionalmente, a capacitação pessoal, associada ao desenvolvimento do projeto, contribui para aprimorar as habilidades da equipe de profissionais que assistem aos portadores de Síndrome de Down em Goiás.

O projeto Alfadown é uma experiência universitária que pode até ser replicada em outras universidades ou instituições educativas, pois outra inovação do projeto está na capacidade de agregar a contribuição das diversas áreas do conhecimento - Pedagogia, Psicologia, Ciências da Saúde, Engenharia, entre 
outras - para favorecer a inclusão e a participação social das pessoas com SD, promovendo a elas maior qualidade de vida em seus contextos. As principais condições para a efetivação desse projeto são: articulação ensino, pesquisa e extensão na vivência da inclusão social, disponibilidade de espaço físico para o atendimento dos educandos e suas famílias com salas de convivência e laboratórios de informática, professores universitários da área pedagógica e psicológica com carga horária destinada para o projeto para formação, gestão e acompanhamento do grupo de acadêmicos e de familiares, reuniões de planejamento, avaliação, estudo e pesquisa para a qualificação dos trabalhos.

Em nossa realidade atual, dentre as contribuições científicas e tecnológicas do trabalho, destacam-se os seguintes resultados:

Criação de um ambiente em que os alunos dos diversos cursos da PUC GOIAS vivenciam uma prática pedagógica com pessoas com Síndrome de Down (SD), contribuindo na alfabetização desses educandos, além de favorecer no desenvolvimento de suas habilidades sociais.

Consolidação do grupo de estudo sobre o processo de ensino-aprendizagem de pessoas com Síndrome de Down, embasamento teórico-prático sobre questões relativas à Educação Inclusiva.

Produção de Teses, Dissertações, Trabalhos de Conclusão de Curso, Artigos, Banners, considerando as análises das aplicações dos recursos computacionais na perspectiva de auxílio da mediação pedagógica no processo de ensino-aprendizagem, favorecendo uma maior compreensão da utilização da tecnologia no contexto educacional.

Desenvolvimento de atividades pedagógicas com o uso de recursos computacionais para auxiliar no processo de alfabetização vivido por pessoas com Síndrome de Down.

Estabelecimento de parceria com a Engenharia da Computação para o desenvolvimento de um aplicativo (software) com a finalidade de promover a Inclusão Digital.

Consolidação do grupo Psicoeducativo de Pais, com a finalidade de estimular a Família Down, contudo ministramos palestras com o intuito de envolver os pais da criança com Down na perspectiva pedagógica, para que nossa ação seja contínua.

A vivência do Alfadown procura trazer contribuições educativas a todos os envolvidos, seja por parte de qualquer segmento no projeto - professores, acadêmicos, educandos e familiares. Essa experiência do projeto busca ser um percurso transformativo, pretendendo alterar concepções, posturas pessoais, teóricas, acadêmicas, profissionais e além, do que já foi mencionado 
anteriormente, esforça-se para proporcionar significativa qualidade de vida a seus integrantes, oportunizando a apropriação de valores essenciais para si e para o convívio social, especialmente para os educandos atendidos.

Para isso, tentamos desenvolver atividades que promovam de forma consistente, através de uma vivência prática, concreta, em relação a descoberta de valores essenciais para o ser humano. Como nos disse Celso Antunes(2012), "Valor é um fim, algo para o qual a ação humana pode e deve se dirigir, aquilo que "vale a pena"; valor é o que dá sentido à atividade e, no limite, à vida.

Compartilhamos do pensamento desse autor acreditando que, dentre todos os valores trabalhados com os participantes do Alfadown, a autonomia é o valor que se destaca na experiência do projeto, no qual a equipe empenha-se que seus integrantes se apropriem de forma prática desse valor tão significativo. Sobre esse tema José Pacheco (2012) nos diz

\footnotetext{
A autonomia exprime-se na relação EU-TU, no sentido que Martin Buber lhe outorga.

É, essencialmente, com os pais e os professores que a criança encontra os limites de um controle que lhe permite progredir numa autonomia, que é liberdade de experiência e de expressão dentro de um sistema de relações e de trocas sociais. Conclusão: a autonomia convive com a solidariedade.
}

Segundo o autor, a autonomia, não se trata de uma concepção isolada, mas está sempre atrelada a autoestima, autocontrole, autoconfiança, levando à liberdade. O sujeito se diferencia do outro, quando lhe é dada a possibilidade de ser quem é, sendo acolhido e reconhecido na sua complexidade e individualidade e também na dependência da coletividade. Esse valor tem sido assumido de forma gradual, integral e responsavelmente na atuação da equipe Alfadown.

No decorrer de todo o processo de participação no projeto Alfadown, é notório os avanços de todos os participantes do projeto, observados a partir dessa relação Eu-Tu. Nessa perspectiva a qualidade de vida está intimamente ligada ao desenvolvimento de uma boa Educação, na formação de cidadãos, através da alfabetização das pessoas com SD, dando a elas a oportunidade de ampliar suas possibilidades de comunicação, gerando participação ativa e responsabilidade social, atitudes de autorreflexão e ações éticas, dentro de uma consciência sustentável de pertencimento ao coletivo.

Educandos como o Patrick Santana, que chegava aos atendimentos resistente em integrar-se com os demais, pelo fato de apresentar um contexto familiar delicado, com histórico de agressão, hoje, progressivamente tem compartilhado 
suas vivências com os voluntários e professores do projeto e buscado estar mais atento às propostas de atividades. Muitas vezes, ao final dos atendimentos, demonstra o desejo de permanecer junto aos voluntários, para continuar convivendo e compartilhando suas histórias com eles.

Gustavo, por exemplo, é um educando já alfabetizado, que permanece participando do projeto, porque notamos que o projeto tem possibilitado a ele, relacionar-se com outras pessoas e até mesmo poderá vir a colaborar com os demais educandos em processo de alfabetização.

\section{RELATO DE UMA FAMÍLIA}

Os voluntários também tem compartilhado suas experiências na atuação junto aos educandos. A aluna do curso de fisioterapia, Janaina Bueno, fez o seu relato sobre sua experiência no Alfadown:

"O ganho que alunos e monitores tem com o projeto é significante, pois alunos e monitores ficam estimulados a darem o seu melhor. O projeto, as atividades e a relação que existe entre monitor e aluno aproxima o conhecimento e desenvolve o aprendizado de cada um, induzindo o aluno a crescer educacionalmente como pessoalmente em relação ao projeto. O projeto fornece um crescimento estrutural e emocional e nos ajuda a amadurecer, pois possibilita, na prática, o processo de inclusão e interação com pessoas com a Síndrome de Down, nos preparando para lidar com as diferenças.”

\section{RELATO DA GOORDENAÇÃO}

Acreditamos que os depoimentos registrados, são uma comprovação da melhoria nas relações interpessoais de toda a equipe Alfadown, assim como, são promotoras de aprendizagem, impactando significativamente na qualidade de vida dos envolvidos, na saúde emocional do educando, de sua família, no acolhimento à diversidade.

\section{CONCLUSÃO}

Os novos paradigmas e interfaces para a interação entre o homem e a máquina vêm influenciando as relações humanas, o cotidiano e a cultura. Hoje, 
vivenciamos a era pós-PC, na qual o computador (hardware) está embutido em diferentes objetos do cotidiano, como, carros, eletrodomésticos e, até mesmo, na indumentária. Da mesma forma, passamos a utilizar o software para acesso a diferentes tipos de serviço, a qualquer hora, em qualquer lugar, como, por exemplo, no agendamento de uma consulta médica ou, até mesmo, para uma solenidade numa rede social.

Adicionalmente, como paradigma da Computação, a Realidade Virtual e/ ou Aumentada possibilita ampliar a interação humano-computador, por meio de interfaces habilitadas para produzir, perceber e reagir diante de diferentes estímulos, tendo como origem os diferentes sentidos do corpo humano e/ou gerados artificialmente pelo computador.

É consensual que a estimulação adequada possibilita a aceleração do desenvolvimento neuropsíquico e social. Assim sendo, no contexto do projeto Alfadown, vêm sendo desenvolvidas novas tecnologias de realidade aumentada que podem contribuir no processo de alfabetização vivido por pessoas com Síndrome de Down, como, por exemplo, software para execução de atividades de letramento e vocalização, reconhecimento e compreensão do contexto e, até mesmo, para o auxílio no aprendizado das atividades funcionais e sociais da vida diária, como, atravessar uma avenida ou ir ao shopping.

As atividades do Alfadown usam recursos como interfaces touchscreen, ambientes com simulação 3D e a adaptação de sensores às interfaces tradicionais, como, o mouse e o gamepad para desenvolver habilidades e promover a apropriação do conhecimento dos participantes do Projeto. Noutra direção, novas tecnologias que incorporam também a realidade aumentada estão sendo desenvolvidas para a verificação e a validação dos processos e das atividades de ensino-aprendizagem, como, por exemplo, o monitoramento automático de variáveis fisiológicas e comportamentais que podem influenciar na consecução e no desempenho das atividades durante o treinamento, como, o estresse, a ansiedade, a desatenção e o desinteresse. Além disso, o desenvolvimento de novas ferramentas de trabalho para a prática terapêutica, como, por exemplo, um espelho virtual, para ser utilizado no estímulo da fala, capaz de fornecer informações fisiológicas e comportamentais, além de recursos gráficos que podem ser utilizados pelo fonoaudiólogo durante a sessão. Tudo isso, corrobora com a tendência verificada em descentralizar a prestação de serviços em Saúde e em Educação.

Portanto, antevê-se que o projeto Alfadown poderá ser estendido no futuro para alcançar limites fora da PUC Goiás, como, a comunidade e o ambiente 
doméstico do educando, por meio da tecnologia da informação, de novas metodologias e ferramentas que possibilitem verificar, avaliar e customizar a execução das atividades, à distância, pela Internet.

Desse modo, poderá favorecer uma inclusão na sociedade tecnológica das pessoas beneficiadas, além de criar um ambiente favorável aos alunos das Licenciaturas e Bacharelado no que se refere à capacitação para questões relativas à Educação Inclusiva.

\section{REFERÊNCIAS}

BOFF, Leonardo. Críticos, Criativos, cuidantes. Educação Cidadão: Novos Atores, nova Sociedade. Caderno de Estudos 02. Talher Nacional. Brasília-DF: Centro Cultural Banco do Brasil, p. 7-8, 2004.

CASTELLS, Manuel. A sociedade em rede. São Paulo, Editora Zahar, 2003.

UCG-Universidade Católica de Goiás. Política de Extensão. Goiânia: UCG, 2006.

1 Agradecemos ao Fundo de Amparo à Ciência e Tecnologia do Estado de Goiás (FAPEG) e o Ministério da Comunicação pela concessão de bolsa de pesquisa que permitiu a realização do presente relato de experiência.

2 Endereço de correspondência: Juliana Santos de S. Hannum, Goiânia 74230-045, Brasil. Contato: dra.julianahannum@yahoo.com.br 